\title{
ANALISIS DESTINATION BRANDING KAWASAN WISATA TAMAN SARI MELALUI METODE IMPORTANCE PERFORMANCE ANALYSIS
}

\author{
Novi Irawati ${ }^{1}$, Sabda Elisa Priyanto ${ }^{2}$, Yuliana Pinaringsih Kristiutami ${ }^{3}$ \\ ${ }^{1}$ Sekolah Tinggi Pariwisata Ambarrukmo Yogyakarta, Indonesia, Email: irawati_novie@yahoo.co,id \\ ${ }^{2}$ Sekolah Tinggi Pariwisata Ambarrukmo Yogyakarta, Indonesia, Email: sabda.priyanto@gmail.com \\ ${ }^{3}$ Akademi Pariwisata BSI Bandung, Indonesia, Email: yuliana.pinaringsih@gmail.com
}

\begin{abstract}
ABSTRAK
Histori Artikel

Submitted:

1 September 2019

Reviewed:

14 September 2019

Accepted:

1 Oktober 2019

Published:

15 November 2019

Sebagai bagian dari upaya untuk memasarkan Taman Sari melalui Destination branding dinilai memiliki peranan penting untuk dapat meningkatkan jumlah kunjungan wisatawan. Penelitian ini menggunakan pendekatan kualitatif, pendekatan kualitatif digunakan supaya mendapatkan informasi yang selengkap mungkin mengenai strategi pemasaran pariwisata melalui upaya Destination Branding. Hasil penelitian ini mengungkapkan bahwa Taman Sari dalam menerapkan strategi Destination branding kurang terencana denggan sistematis, sehingga Destination branding hanya dipahami secara sempit yakni hanya pada aspek visualisasi. Sehingga program-program pada pengembangan produk pariwisata sedikit bertabrakan dengan konsep

Destination branding yang telah dibentuk dari awal.
\end{abstract}

Kata Kunci : Pemasaran Pariwisata, Destination Branding, Taman Sari

\begin{abstract}
Taman Sari Tourism Marketing Strategy Through Destination branding has tourism potential through culture and historical value. With this potential, the government is managing tourism in order to be able to move the economy in Taman Sari. In realizing this vision, planning and strategy are needed, one of which is Destination Branding. Destination branding is used in every tourism site in the world and is able to make a good impact on the progress of tourism, for example are the Twin Towers in Malaysia, the Merlion Statue in Singapore, the Taj Mahal in India, etc. Destination branding has an important role to be able to increase the number of tourist visits. This study uses a qualitative approach, a qualitative approach is used in order to get complete information about tourism marketing strategies with Destination Branding. The results of this study found that the Destination branding strategy in Taman Sari is not planned systematically, so that Destination branding is only understood in a small way, that is only in the visualization aspect. So that tourism product development programs are not in accordance with the concept of Destination branding that has been made.
\end{abstract}

Keywords : Tourism Branding, Destination branding, Taman Sari 


\section{PENDAHULUAN}

Undang-undang otonomi daerah memberikan angin segar bagi berbagai pemerintah daerah untuk dapat memajukan daerah masing-masing dengan berbagai potensi yang ada. Salah satu wujudnya beberapa kepala daerah mulai menawarkan potensi daerah sebagai upaya untuk meningkatkan Pendapatan Asli Daerah (PAD) dan secara lebih luas diharapkan dapat meningkatkan kesejahteraan bagi masyarakat. Potensi daerah ibarat sebuah produk atau jasa dikemas dan diberi merek (branding) agar memiliki ciri yang dapat membedakan dengan potensi daerah lainnya.

Sektor pariwisata adalah sektor yang sangat penting di dunia. Hal itu Nampak dari keseriusan berbagai negara dalam mengelola sektor pariwisata dengan tujuan supaya menjadi satu tujuan kunjungan wisata internasional dan mampu menyerap tenaga kerja dari masyarakat setempat dan begitu pula dengan Indonesia, khususnya di Yogyakarta. Salah satu daerah yang memiliki potensi wisata di Yogyakarta yakni Taman Sari. Taman Sari yang sangat kental dengan nuansa nilai historicalnya.

Jika dicermati dalam kurun waktu 9 tahun belakang Taman Sari telah mencetuskan branding yang tidak sedikit. Bermula dari tahun 1758 dengan destination brand Taman Sari yang pertama kali yakni The Fragrant Garden hingga sekarang the water castle. Dalam Meidan, 1989:43 strategi pemasaran pariwisata, beberapa langkah penting yang harus dilakukan adalah segmentasi pasar, penentuan pasar sasaran, positioning dan branding (Laksana, Riyanto, \& Said, 2015)

Menurut Kotler \& keller (2009), sebuah brand adalah entitas perseptual yang berakar dalam suatu kenyataan, tetapi mencerminkan persepsi dan bahkan pikiran dan perasaan konsumen. Brand personality adalah bauran spesifik dari sifat manusia yang dimiliki oleh suatu produk atau jasa. Penelitian menunjukkan bahwa brand yang memiliki personalitas akan disukai konsumen karena manusia cenderung memilih brand yang mempunyai personalitas yang cocok dengan personalitas mereka.

Dalam kaitannya dengan permasalahan tersebut, rumusan masalah dalam penelitian ini adalah Bagaimana strategi pemasaran pariwisata di Taman Sari melalui destination branding? Dan apakah strategi yang diimplementasikan di Taman Sari sudah maksimal?

\section{LITERATUR REVIEW}

\section{Pariwisata}

Pariwisata telah menjadi salah satu industri terbesar di dunia, dan merupakan andalan utama dalam menghasilkan devisa. Pariwisata juga lebih dipandang sebagai kegiatan ekonomi, dan tujuan utama pengembangan pariwisata adalah untuk mendapatkan ekonomi, baik bagi masyarakat atau negara itu sendiri (Kristiutami, 2014).

Pariwisata memiliki peran yang besar dalam pembangunan nasional. Karena selain menghasilkan pendapatan dan sekaligus sebagai penghasil devisa, sektor pariwisata berkaitan erat dengan penanaman modal asing. Turis-turis yang datang ke Indonesia adalah termasuk mereka yang berhubungan bisnis dengan Indonesia (Maharani, 2014).

Undang-undang Nomor 10 tahun 2009, menyebutkan pariwisata adalah segala sesuatu yang berhubungan dengan wisata, termasuk pengusahaan obyek dan daya tarik wisata serta usaha-usaha yang berhubungan dengan penyelenggaraan pariwisata, dengan demikian pariwisata meliputi semua kegiatan yang berhubungan dengan perjalanan wisata, pengusahaan obyek dan daya tarik wisata serta pengusahaan jasa dan sarana pariwisata (Widiastuti, 2013).

Setidaknya Pariwisata harus memiliki daya tarik yang dapat menarik wisatawan untuk mengunjungi wilayah tertentu. Pariwisata menurut daya tariknya dapat dibedakan menjadi 3 bagian, yaitu daya tarik wisata alam, daya tarik wisata budaya, dan daya tarik wisata minat khusus.

Wisata pada daya tarik alam yaitu wisata yang dilakukan dengan mengunjungi daerah 
tujuan wisata yang memiliki keunikan daya tarik alamnya, seperti laut, pesisir pantai, gunung, lembah, air terjun, hutan dan objek wisata yang masih alami.

Wisata pada daya tarik budaya merupakan suatu wisata yang dilakukan mengunjungi tempat-tempat yang memiliki keunikan atau kekhasan budaya,seperti kampung naga, tanah toraja, kampung adat banten, kraton kasepuhan Cirebon, kraton Yogyakarta, dan objek wisata buidaya lainnya.

Sedangkan yang dimaksud dengan wisata pada daya tarik wisata minat khusus adalah wisata yang dilakukan dengan mengunjungi objek wisata yang sesuai dengan minat seperti wisata olahraga, wisata rohani, wisata kuliner, wisata belanja, dengan jenis-jenis kegiatannya antara lain bungee jumping (Fandeli, 1995, h.3).

\section{Pemasaran Pariwisata}

Definisi pemasaran menurut American Marketing Association (AMA) seperti yang dikutip oleh Rhenald Kasali (1998) adalah: "Pemasaran adalah suatu proses perencanaan dan eksekusi, mulai dari tahap konsepsi, penetapan harga,promosi, hingga distribusi barang-barang, ide-ide dan jasa, untuk melakukan pertukaran yang memuaskan individu dan lembaga-lembaganya" (Sepang, Kawet, \& Mandey, 2016).

Secara umum manajemen pemasaran dapat diartikan sebagai suatu seni dan ilmu untuk dapat memilih pasar sasaran, dan mendapatkan, mempertahankan, dan menumbuhkan pelanggan melalui penciptaan, penyampaian, dan pengkomunikasian nilai yang unggul kepada pelanggan" (Kolter dan Keller, 2009). Definisi ini adalah definisi luas dan umum dari pemasaran terutama karena Kotler (1969) berkeyakinan bahwa prinsip-prinsip umum dalam pemasaran akan berlaku untuk produk, jasa, orang, dan tempat (destinasi wisata).

Akan tetapi, walaupun secara umum definisi tersebut bisa diterima dalam rangka tujuan pemasaran wisata, ada beberapa area dimana perencanaan dan pengelolaan pemasaran pariwisata perlu mendapatkan nuansa dan penekanan khusus . Strategi pemasaran yang dapat dibuat meliputi pengembangan tempat dan aktivitas wisata, akomodasi, akses ke tujuan-tujuan wisata, sarana-sarana pendukung pariwisata, dan juga komunikasi pemasaran pariwisata yang efektif dan efisien.

Pemasaran pariwisata adalah suatu proses manajemen yang dilakukan oleh organsiasi pariwisata nasional atau perusahaan-perusahaan yang termasuk dalam kelompok industri pariwisata untuk melakukan identifikasi terhadap wisatawan yang sudah punya keinginan untuk melakukan perjalanan wisata dengan jalan melakukan komunikasi dengan mereka, mempengaruhi keinginan, kebutuhan, dan memotivasinya, terhadap apa yang disukainya, pada tingkat daerah-daerah local, regional, nasional maupun internasional dengan menyediakan objek dan atraksi wisata agar wisatawan memperoleh kepuasaan optimal (Iwan Suryadi 2007 dan Besra, 2012).

\section{Branding}

Brand atau Merek adalah istilah, tanda, simbol, atau rancangan, atau kombinasi halhal tersebut, yang dimaksudkan untuk mengidentifikasi barang atau jasa dari seorang atau sekelompok penjual dan untuk membedakannya dari produk pesaing. (Handayani, 2015)

Branding adalah serangkaian proses dan aktivitas untuk menciptakan suatu brand. Kotler and Keller (2009) mendefinisikan branding sebagai upaya untuk meliputi suatu produk atau jasa dengan kekuatan suatu brand. Menurut mereka, sebuah brand adalah 'entitas perseptual yang berakar dalam suatu kenyataan, tetapi mencerminkan persepsi dan bahkan pikiran dan perasaan konsumen'.

Sedangkan pengertian destination branding menurut Karen Post adalah membrand-kan tempat/ tujuan wisata membuat orang memiliki alasan untuk berkunjung. 
Pengertian destination branding dalam penelitian ini adalah: perancangan suatu tempat (negara) sebagai tujuan wisata yang sesuai dengan inti/jiwa dari negara tersebut agar menarik orang untuk berkunjung. (Sutanto, Natadjaja, \& Erandaru, 2010)

Upaya branding bisa dilakukan dengan banyak cara, akan tetapi yang umum dilakukan adalah dengan menentukan brand personality, brand positioning, dan brand identifiers (brand drivers) (Laksana et al., 2015 dan Gelder, 2005)

Menurut Ritchie and Ritchie ; 1998, Destination branding juga di definisikan sebagai, nama, simbol, logo, word mark atau gambaran lainnya yang dapat mengidentifikasikan dan membedakan sebuah destinasi; selebihnya, menjanjikan sebuah pengalaman wisata yang dapat diingat karena keunikan yang dimiliki oleh sebuah destinasi; yang juga berfungsi dalam memperkuat ingatan, kenangan yang mengesankan dari sebuah pengalaman destinasi. (Rahardipha, Hidayat, \& Widiartanto, 2016)

\section{METODE}

Strategi pemasaran pariwisata melalui Destination branding di Taman Sari, yang meliputi penentuan unsur brand personality, brand positioning, brand identity.

Brand personality Taman Sari dikaji dengan elemen, yaitu brand competence, excitement, dan sincerity
Brand positioning Taman Sari dengan elemen: yaitu nilai keunggulan, brand mantra, dan nilai kesamaan

Brand identity Taman Sari dengan elemen: yaitu relationship, physique, dan self image

Salah satu titik fokus pemerintah daerah sekitar lokasi Taman Sari dalam mengembangan pariwisata adalah melalui pemasaran pariwisata. Untuk mencapai visi Taman Sari yang ingin menjadi daerah tujuan wisata kemudian dilakukan strategi pemasaran pariwisata. Pada perkembanganya Taman Sari yang memang memiliki potensi di bidang pariwisata mulai menerapkan strategi destination branding untuk mengangkat pariwisata di Taman Sari. Berbekal dengan potensi di bidang historical akhirnya Taman Sari membangun branding di tahun 1758 dengan tagline "The Fragrant Garden".

Dengan menerapkan Destination branding di Taman Sari yang cukup intensif, memberikan dampak yang signifikan. Salah satu indikatornya adalah jumlah kunjungan wisatawan yang mengalami kenaikan baik wisatawan domestik maupun wisatawan asing. Pada perkembanganya ternyata Taman Sari mengalami berbagai perubahan. Lalu dengan target baru yang ingin menjadikan Taman Sari sebagai daerah tujuan wisata harusnya dapat berhasil jika proses dalam pembentukan destination branding benarbenar dilakukan dengan tepat melalui 3 tahapan proses yakni brand personality, brand positioning \& brand identifiers.

Tabel 1

Variabel dan atribut penelitian.

\begin{tabular}{|c|c|c|c|}
\hline No & Variable & Atribut & Deskriptor \\
\hline \multirow[t]{3}{*}{1} & Brand Identity & Relationship & $\begin{array}{l}\text { Adanya hubungan antara abdi dalem dengan wisatawan } \\
\text { untuk berbagi sejarah dan budaya taman sari }\end{array}$ \\
\hline & & Physique & $\begin{array}{l}\text { Bangunan taman sari mendeskripsikan situasi masa } \\
\text { lampau }\end{array}$ \\
\hline & & Self image & $\begin{array}{l}\text { Taman sari merupakan tempat rekreasi bagi keluarga } \\
\text { Wisata berbasis sejarah dan budaya untuk mengedukasi } \\
\text { pengunjung wisata taman sari }\end{array}$ \\
\hline \multirow[t]{2}{*}{2} & Brand Personality & $\begin{array}{l}\text { Brand } \\
\text { competence }\end{array}$ & $\begin{array}{l}\text { Mempertahankan keaslian bangunan dan menampilkan } \\
\text { cerita nyata dari unsur historical }\end{array}$ \\
\hline & & Excitement & Daya tarik historical dalam wisata taman sari \\
\hline
\end{tabular}




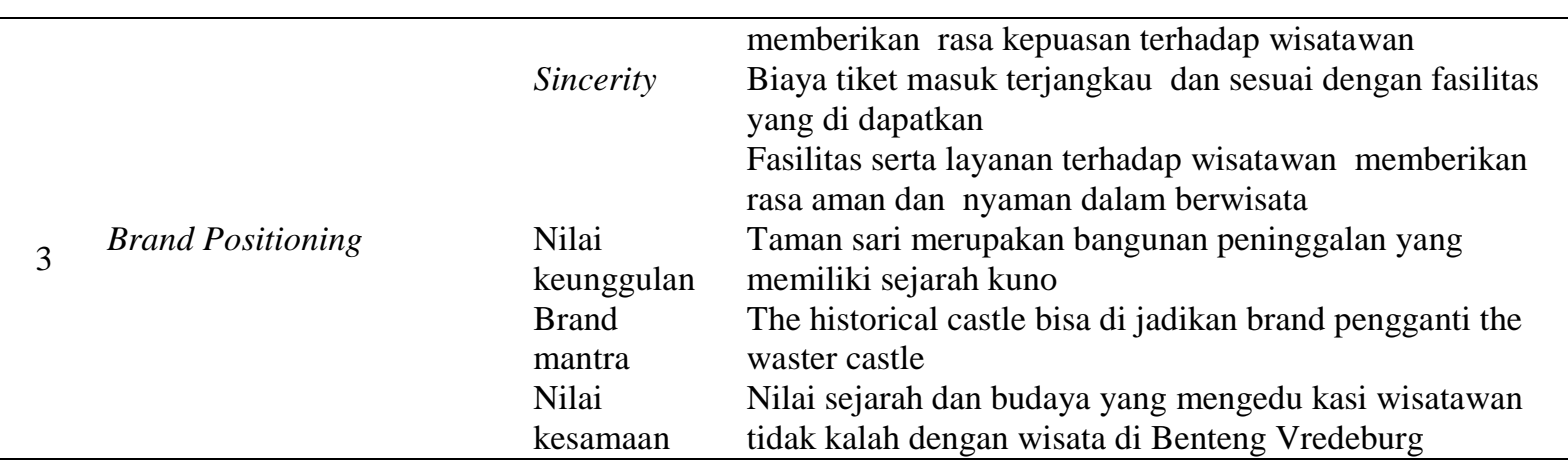

\section{Sumber Data}

Pertama, peneliti telah menentukan untuk mendapatkan sampel sebanyak 25 responden. Setelah jumlah sampel ditentukan maka instumen penelitian dibagikan sebagai sumber data, sumber data yang digunakan diantaranya yaitu kuesioner, dan dokumentasi.

\section{Skala Likert}

Sugiyono (2012) menerangkan bahwa skala Likert digunakan untuk mengukur sikap atau pendapat seseorang atau sejumlah kelompok terhadap sebuah fenomena sosial yang dimana jawaban setiap item instrumen mempunyai gradasi dari sangat positif sampai sangat negatif. Dengan skala likert variabel yang akan diukur dijabarkan menjadi indikator variabel. Kemudian indikator tersebut dijadikan titik tolak untuk menyusun item-item instrumen yang dapat berupa pernyataan atau pertanyaan. Berikut adalah skala yang dipakai pada penelitian ini:
c. Cukup Setuju
d. Setuju
e. Sangat Setuju

\section{Importance Performance Analysis (IPA)}

Menurut Tjiptono (2011) teknik ini dikemukakan pertama kali oleh Martilla dan James pada tahun 1977 dalam artikel mereka "Importance- Performance Analysis" yang dipublikasikan di Journal of Marketing. Pada teknik ini, responden diminta untuk menilai tingkat kepentingan dan kinerja perusahaan, kemudian nilai rata-rata tingkat kepentingan dan kinerja tersebut dianalisis pada Importance-Performance Matrix, yang mana sumbu x mewakili persepsi sedangkan sumbu y mewakili harapan (Rahardipha et al., 2016).

Maka nanti akan didapat hasil berupa empat kuadran sesuai gambar berikut:

a. Sangat Tidak Setuju

b. Tidak Setuju

\begin{tabular}{|c|c|}
\hline A = Prioritas Utama & B = Pertahankan Prestasi \\
\hline $\mathrm{C}=$ Prioritas Rendah & $\mathrm{D}=$ Berlebihan \\
\hline
\end{tabular}

Gambar 1. Kuadran Importance Performance Analisys

Adapun interpretasi dari kuadran diatas Pada kuadaran ini terdapat faktor-faktor yang adalah sebagai berikut: dianggap penting dan atau diharapkan konsumen akan tetapi kinerja perusahaan Prioritas Utama (Concentrate Here) dinilai belum memuaskan sehingga pihak perusahaan perlu berkonsentrasi untuk 
mengalokasikan sumber dayanya guna meningkatkan performa yang masuk pada kuadran ini.

\section{Pertahankan Prestasi (Keep Up The Good Work)}

Pada kuadaran ini terdapat faktor-faktor yang dianggap penting dan diharapkan sebagai faktor penunjang kepuasan konsumen sehingga perusahaan wajib untuk mempertahankan prestasi kinerja tersebut.

\section{Prioritas Rendah (Low Priority)}

Pada kuadaran ini terdapat faktor-faktor yang dianggap mempunyai tingkat persepsi atau kinerja aktual yang rendah dan tidak terlalu penting dan atau tidak terlalu diharapkan oleh konsumen sehingga perusahaan tidak perlu memprioritaskan atau memberikan perhatian lebih pada faktor-faktor tersebut.
Pada kuadaran ini terdapat faktor-faktor yang dianggap tidak terlalu penting dan tidak terlalu diharapkan oleh pelanggan sehingga perusahaan lebih baik mengalokasikan sumber daya yang terkait pada faktor tersebut kepada faktor lain yang lebih memiliki tingkat prioritas lebih tinggi.

\section{HASIL DAN PEMBAHASAN}

Tabel 2 hasil penelitian ini menjelaskan bahwa diketahui kebanyakan atribut memiliki nilai negatif yang berarti bahwa kebanyakan dari atribut tersebut belum memenuhi harapan pelanggan. Dari data tersebut maka perlu analisis lebih lanjut untuk menentukan skala prioritas dalam usaha perbaikan dari setiap atribut yang ada, adapun cara untuk menentukan skala prioritas pembenahan yang ada adalah dengan menggunakan metode Importance Performance Analysis (IPA).

\section{Berlebihan (Possibly Overkill)}

Tabel 2

Hasil Penelitian

\begin{tabular}{|c|c|c|c|c|}
\hline \multirow{2}{*}{ No } & \multirow{2}{*}{ Deskriptor } & \multicolumn{2}{|c|}{ Skor } & \multirow{2}{*}{$\begin{array}{c}\text { Skor } \\
\text { Kepuasan }\end{array}$} \\
\hline & & Persepsi & Ekspekasi & \\
\hline 1 & $\begin{array}{l}\text { Adanya hubungan antara abdi dalem dengan wisatawan untuk } \\
\text { berbagi sejarah dan budaya taman sari }\end{array}$ & 3.00 & 3.00 & 0 \\
\hline 2 & Bangunan taman sari mendeskripsikan situasi masa lampau & 4.20 & 5.00 & $-0,8$ \\
\hline 3 & Taman sari merupakan tempat rekreasi bagi keluarga & 2.64 & 3.00 & $-0,36$ \\
\hline 4 & $\begin{array}{l}\text { Wisata berbasis sejarah dan budaya untuk mengedukasi } \\
\text { pengunjung wisata taman sari }\end{array}$ & 4.32 & 5.00 & $-0,68$ \\
\hline 5 & $\begin{array}{l}\text { Mempertahankan keaslian bangunan dan menampilkan cerita } \\
\text { nyata dari unsur historical }\end{array}$ & 3.92 & 4.00 & $-0,08$ \\
\hline 6 & $\begin{array}{l}\text { Daya tarik historical dalam wisata taman sari memberikan } \\
\text { rasa kepuasan terhadap wisatawan }\end{array}$ & 3.96 & 4.00 & $-0,04$ \\
\hline 7 & $\begin{array}{l}\text { Biaya tiket masuk terjangkau dan sesuai dengan fasilitas yang } \\
\text { di dapatkan }\end{array}$ & 4.00 & 4.00 & 0 \\
\hline 8 & $\begin{array}{l}\text { Fasilitas serta layanan terhadap wisatawan memberikan rasa } \\
\text { aman dan nyaman dalam berwisata }\end{array}$ & 3.84 & 4.00 & $-0,16$ \\
\hline 9 & $\begin{array}{l}\text { Taman sari merupakan bangunan peninggalan yang memiliki } \\
\text { sejarah kuno }\end{array}$ & 4.64 & 5.00 & $-0,36$ \\
\hline 10 & $\begin{array}{l}\text { The historical castle bisa di jadikan brand pengganti the waster } \\
\text { castle }\end{array}$ & 4.36 & 4.50 & $-0,14$ \\
\hline 11 & $\begin{array}{l}\text { Nilai sejarah dan budaya yang mengedu kasi wisatawan tidak } \\
\text { kalah dengan wisata di Benteng Vredeburg }\end{array}$ & 4.24 & 4.50 & $-0,26$ \\
\hline
\end{tabular}

Pada bagian ini dibahas mengenai pemetaan

dari nilai kinerja (x) dan harapan (y), dari 
hasil tersebut maka akan terbentuk matriks yang terdiri dari empat buah kuadran yang masing-masing kuadran menggambarkan skala prioritas dalam mengambil kebijakan baik berupa peningkatan kinerja atau mempertahankan kinerja perusahaan. Berikut adalah data sebaran kinerja dan harapan pelanggan.

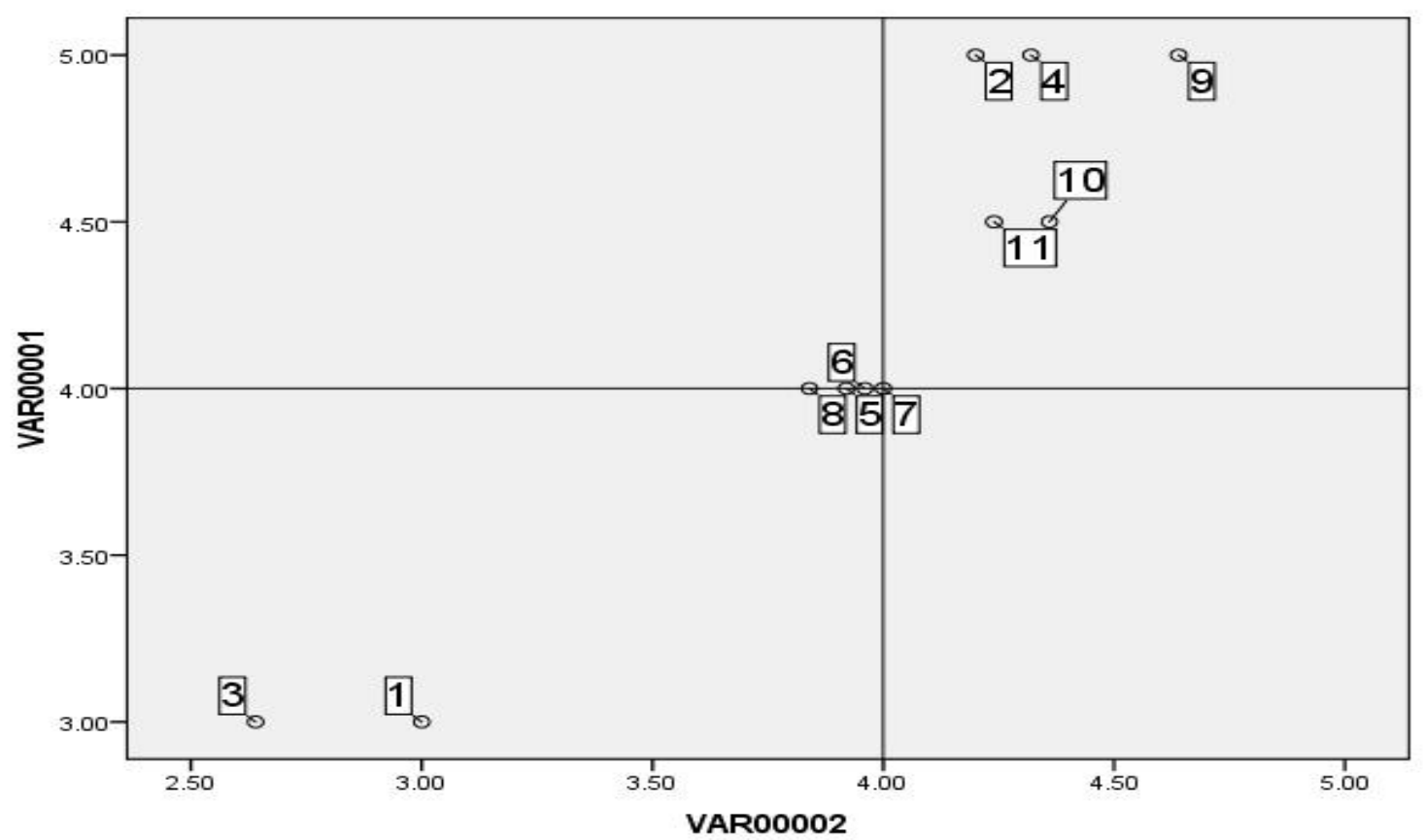

Gambar 2. Data sebaran kinerja dan harapan pelanggan

Dari gambar tersebut maka dapat diinterpretasikan sebagai berikut:

\section{Kuadran A}

Kuadran A menunjukkan faktor atau atribut yang dianggap penting oleh pelanggan namun tidak terlaksanakan dengan baik oleh perusahaan. Variabel-variabel yang termasuk dalam kuadran ini adalah: (6) Daya tarik historical dalam wisata taman sari memberikan rasa kepuasan terhadap wisatawan. Dengan demikian item-item tersebut menjadi skala prioritas utama perusahaan untuk diperbaiki.

\section{Kuadran B}

Kuadran B menunjukkan faktor atau atribut yang dianggap penting dan memuaskan pelanggan yang sudah dilaksanakan dengan baik oleh perusahaan. Variabel-variabel yang termasuk dalam kuadran ini adalah: (2) Bangunan taman sari mendeskripsikan situasi masa lampau (4) Wisata berbasis sejarah dan budaya untuk mengedukasi pengunjung wisata taman sari (9) Taman sari merupakan bangunan peninggalan yang memiliki sejarah kuno (10) The historical castle bisa di jadikan brand pengganti the water castle (11) Nilai sejarah dan budaya yang mengedukasi wisatawan tidak kalah dengan wisata di benteng Vredeburg. Dengan demikian, item-item tersebut perlu dipertahankan kinerjanya oleh pihak perusahaan.

\section{Kuadran C}

Kuadran C menunjukkan faktor yang dianggap kurang penting oleh pelanggan dan tidak terlaksanakan dengan baik oleh perusahaan. Variabel-variabel yang termasuk dalam kuadran ini adalah: (1) Adanya hubungan antara abdi dalem dengan wisatawan untuk berbagi sejarah dan budaya taman sari (3) Taman sari merupakan tempat rekreasi bagi keluarga (5) 
Mempertahankan keaslian bangunan dan menampilkan cerita nyata dari unsur historical (8) Fasilitas serta layanan terhadap wisatawan memberikan rasa aman dan nyaman dalam berwisata. Dengan demikian item-item diatas dapat diabaikan/mempunyai skala prioritas pembenahan bagi perusahaan.

\section{Kuadran D}

Kuadran D menunjukkan faktor atau atribut yang dianggap kurang penting oleh perusahaan namun dilaksanakan dengan berlebihan oleh perusahaan. Variabelvariabel yang termasuk dalam kuadran ini adalah: (7) Biaya tiket masuk terjangkau dan sesuai dengan fasilitas yang di dapatkan. Dengan demikian item-item tersebut berlebihan dilaksanakan oleh perusahaan, untuk itu lebih baik pihak perusahaan mengalokasikan sumber dayanya untuk prioritas utama terlebih dahulu.

\section{SIMPULAN}

Berdasarkan hasil perhitungan skor strategy destination branding yang telah dilakukan yang meliputi brand identity, brand positioning dan brand personality, dapat diketahui lima item yang telah memenuhi ekspektasi wisatawan. Dengan analisis Importance Performance Analysis (IPA) juga, maka dapat diketahui bahwa implementasi dari destination branding di taman sari hanya berfokus kepada tiket masuk yang sangat terjangkau oleh seluruh kalangan. Strategi yang telah diterapkan ini adalah kurang tepat dan terbukti bahwa strategi ini masuk dalam kuadran D (berlebihan) dalam metode IPA.

Selanjutanya, masih terdapat beberapa strategi-strategi di taman sari yang masih belum maksimal yang bisa saja dikembangkan untuk mewujudkan pemasaran yang kredibel.

\section{REFERENSI}

B. Susanto, Himawan Wijanarko. (2004). Power branding, Membangun merek unggul dan organisasi pendukungnya. Jakarta, Penerbit Mizan.

Hari Karyono. (1997). Kepariwisataan. Jakarta, Grasindo.

Fitri Adona, Sri Nita, Yusnani dan Luth Mafrudoh. (2017). "City Branding: Strategi Pemasaran Pariwisata Kota Padang" dalam Prosiding Seminar Nasional Multi Disiplin Ilmu \&Call For Papers Unisbank Ke-3(SENDI_U 3) ISBN: 9-789-7936-499-93

Kotler, Philip. (2005). Manajamen Pemasaran. Jakarta, PT. Indeks. Kelompok Gramedia

Besra, E. (2012). Potensi Wisata Kuliner Dalam Mendukung Pariwisata Di Kota Padang. Jurnal Riset Akuntansi Dan Bisnis, 12(1), 74-101.

Handayani, R. (2015). Personal Branding Pustakawan Di Perpustakaan. Jurnal Kajian Informasi Dan Pustakawan, 7(1), 101-110.

Kristiutami, Y. P. (2014). Kawasan Produksi Seni Pahat Batu Sebagai Daerah Tujuan Wisata Di Kabupaten Magelang.

Pariwisata, I(2), 64-71.

Laksana, B. P., Riyanto, \& Said, A. (2015). Strategi Pemasaran Pariwisata Kota Surakarta Melalui City Branding (Studi pada Dinas Pariwisata \& Kebudayaan Kota Surakarta). Jurnal Administrasi Public, 3(1), 73-79.

Maharani, D. P. (2014). Pengembangan Potensi Pariwisata Kabupaten Sumenep, Madura, Jawa Timur (Studi Kasus: Pantai Lombang). Jurnal Politik Muda, 3(3), 412-421.

Rahardipha, L. A., Hidayat, W., \& Widiartanto. (2016). Analisis Program Destination branding Provinsi Nusa Tenggara Barat. Jurnal Ilmu 
Administrasi Bisnis, 5(1).

Sepang, D., Kawet, L., \& Mandey, S. (2016). Diversivikasi Produk, Harga Dan Kualitas Pelayanan Terhadap Kepuasan Pengguna Transvision Manado. Jurnal Berkala Ilmiah Efisiensi, 16(01), 244256.

Sutanto, R. P., Natadjaja, L., \& Erandaru. (2010). Komparasi Destination branding dalam Official Website Negara. Jurnan Desain Komunikasi Visual Nirmana, 12(1), 9-19.

Widiastuti, N. K. (2013). Pengaruh Sektor Pariwisata Terhadap Kinerja Keuangan Daerah Dan Kesejahteraan Masyarakat Kabupaten/Kota Di Provinsi Bali. EJurnal Ekonomi Dan Bisnis Universitas Udayana, 2(5), 292-311.

\section{BIODATA PENULIS}

Novi Irawati, merupakan dosen tetap di Sekolah Tinggi Pariwisata Ambarrukmo, bidang kajian teknik perencanaan arsitektur daerah.

Id Scholar:

https://scholar.google.co.id/citations?hl=id\& authuser=1\&user=I5QGaRMAAAAJ

Sabda Elisa Priyanto, merupakan dosen tetap di Sekolah Tinggi Pariwisata Ambarrukmo Yogyakarta, bidang kajian pariwisata.

Id Scholar:

https://scholar.google.co.id/citations?hl=id\& authuser=1\&user=Kp2OjYYAAAAJ

\section{Yuliana Pinaringsih Kristiutami,} merupakan dosen tetap Akpar BSI Bandung. Bidang kajian manajemen pariwisata Id Scholar: https://scholar.google.co.id/citations?user=Pu pU2LgAAAAJ\&hl=id\&authuser=1\&oi=sra 